\title{
CANDIDATO, PARTIDO E COLIGAÇÃO NA REELEIÇÃO DO PODER EXECUTIVO ESTADUAL ${ }^{1}$
}

\author{
Jayane Maia $^{2}$
}

\begin{abstract}
Resumo
A geografia eleitoral no Brasil, em tempos recentes, tem ganhado força como um instrumento de análise da dinâmica eleitoral no país, enfatizando tanto as estratégias políticas usadas pelos candidatos quanto o comportamento do eleitorado na respectiva região. Investigar em termos quantitativos e geográficos a dinâmica da proporção de votos recebida por um candidato entre uma eleição e outra bem como a possibilidade de regularidades subjacentes à distribuição espacial desses votos é um passo inicial para identificar os determinantes do sucesso eleitoral em eleições consecutivas para o cargo. O estudo objetivou verificar se o candidato e/ou partido reeleito para o executivo estadual manteve o mesmo grau de apoio entre as eleições e como esse apoio foi distribuído no respectivo estado. Observou-se em qual cenário o nível de apoio é maior, estável ou menor, considerando quando é o candidato ou o partido que tentam se reeleger ou quando o partido tenta se manter no poder se inserindo em uma coligação partidária. Analisaram-se as votações recebidas por uma amostra de candidatos, partidos e coligações reeleitos a partir de uma amostra de estados, considerando quatro eleições - 1998, 2002, 2006 e 2010. Os dados amostrais indicam que a possibilidade de sucesso de reeleição e de manutenção da votação nos municípios é maior quando o partido lança o mesmo candidato que foi vitorioso na eleição anterior. Constatou-se ainda que a reeleição do candidato se relaciona com dispersão da diferença positiva da proporção de votos entre eleições e que a reeleição do partido direciona para a concentração dessa diferença. Os dados encontrados orientam para a corrente da literatura que aponta a existência do personalismo político no Brasil, sendo que a reeleição tende a ser mais propensa quando o mesmo candidato concorre à reeleição.
\end{abstract}

Palavras-chave: reeleição, geografia eleitoral, executivo estadual.

\begin{abstract}
The electoral geography in Brazil in recent times has gained strength as an analytical tool of electoral dynamics in the country, emphasizing both the political strategies used by candidates and the electorate's behavior in their region. Investigate quantitative and geographical terms the dynamics of the proportion of votes received by a candidate from an election and another and the possibility of regularities underlying the spatial distribution of these votes is a first step to identify the determinants of electoral success in consecutive elections for the position. The study aimed to verify whether the candidate and / or party re-elected to the state executive maintained the same level of support between elections and how this support was distributed in the respective state. It was observed in the level of support which scenario is most stable or lower, considering when the candidate or the party trying to be reelected or when the party attempts to remain in power by inserting in a party coalition. Analyzed the votes received by a sample of candidates, parties and coalitions reelected from a sample of states, considering four elections - 1998, 2002, 2006 and 2010. The sample data indicate that the possibility of successful re-election and maintenance the vote in the municipalities is higher when the party launches the same candidate was victorious in the previous election. It noted also that the applicant's re-election relates to dispersion of the positive difference in the proportion of votes between elections and the re-election of the party directs to the concentration of that difference. The findings guide to the current literature that indicates the existence of political personalism in Brazil, and the re-election tends to be more likely when the same candidate running for re-election.
\end{abstract}

Keywords: re-election, electoral geography, state executive.

\footnotetext{
${ }^{1}$ DOI deste artigo: $10.5380 /$ recp.v6i1.39048.

2 Bacharela em Ciência Política (Universidade de Brasília) e mestranda em Sociologia (Universidade de Brasília). E-mail: jayane.maia08@gmail.com.
} 


\section{Resumen}

La geografía electoral en Brasil en los últimos tiempos ha cobrado fuerza como instrumento de análisis de las dinámicas electorales en el país, destacando tanto las estrategias políticas utilizadas por los candidatos y el comportamiento del electorado en su región. Investigar cuantitativamente y geográficamente la dinámica de la proporción de votos recibidos por un candidato de una elección y otra, y la posibilidad de regularidades que subyacen a la distribución espacial de estos votos es un primer paso para identificar los determinantes del éxito electoral en elecciones consecutivas para el puesto. El estudio tuvo como objetivo verificar si los candidatos y / o partido re-elegidos para el ejecutivo estatal mantienen el mismo nivel de apoyo entre las elecciones y cómo este apoyo se distribuyó en el estado respectivo. Observado en qué escenario el nivel de apoyo és más alto, estable o menor, teniendo en cuenta que el candidato o el partido tratando de ser reelegidos o cuando la parte que intenta permanecer en el poder mediante la inserción en una coalición de partidos. Analizados los votos recibidos por una muestra de los candidatos, los partidos y coaliciones reelegido de una muestra de estados considerando cuatro elecciones - 1998, 2002, 2006 y 2010. Los datos de la muestra indican que la posibilidad de éxito de la reelección y el mantenimiento de votación en los municipios es mayor cuando el partido indica el mismo candidato obtuvo la victoria en las elecciones anteriores. También señaló que la reelección del candidato se refiere a la dispersión de la diferencia positiva en la proporción de votos entre las elecciones y la reelección del partido dirige a la concentración de esa diferencia. Los resultados guían a la literatura actual que indica la existencia de personalismo político en Brasil, teniendo em cuenta que la reelección tiende a ser más probable cuando el mismo candidato compite a la reelección.

Palabras-clave: de reelección, geografía electoral, ejecutivo estatal.

\section{INTRODUÇÃO}

No cenário de competição política em que candidatos e partidos disputam as preferências dos eleitores, a ciência política ligada à geografia eleitoral procura desvendar o porquê de alguns deles receberem maior apoio político em determinados lugares do que em outros (SOARES \& TERRON, 2008, p. 275). Entretanto, antes de procurar justificativas para a distribuição espacial dos votos para determinado candidato ou político, se faz necessário identificar qual é essa distribuição e qual a sua dinâmica de uma eleição para outra.

A literatura sobre geografia do voto no Brasil ainda é escassa e requer ampliação, de modo que poucos estudos existentes sobre o tema se debruçam sobre a centralidade da dimensão geográfica nas reeleições. Verificar a dinâmica e a distribuição da votação de um candidato em uma eleição e entre eleições é um passo importante que deve compor a tentativa de se explicar a sua vitória nas urnas. Conforme aponta Raymond Aron (1985), a distribuição dos votos revela a heterogeneidade geográfica da opinião pública, sendo que estudos nesse sentido contribuem tanto para o entendimento de estratégias políticas utilizadas pelos candidatos quanto para a compreensão, ainda que superficial, do comportamento do eleitorado em uma região.

De igual forma, a análise da proporção de votos recebida pelo candidato/partido vitorioso em um contexto de reeleição, comparando-se entre anos e entre municípios, no caso brasileiro, mostra-se de grande relevância na medida em que se pode verificar onde 
houve maior ou menor grau de apoio ao reeleito. Sabendo disso, pode-se, a posteriori, avaliar a intensidade da associação entre status socioeconômico e comportamento eleitoral, por exemplo. No entanto, deve-se considerar também que o comportamento do eleitor seja direcionado puramente por expectativas clientelistas, seja flexível de acordo com as circunstâncias conjunturais do momento ou se baseie em atalhos de informação captados durante a campanha - imagem do candidato, uma política que deu ou não certo, etc. O mais provável é que decisão do voto seja transpassada por todas essas variáveis e, por isso, seja fruto, mais do que se pode imaginar, de processos altamente dinâmicos (LAMOUNIER, 1978).

Nesse sentido, o objetivo principal do estudo é verificar se o candidato e/ou partido reeleito para o executivo estadual manteve o mesmo grau de apoio entre as eleições e como esse apoio foi distribuído no respectivo estado. Não se deseja aqui delimitar a estratégia política vitoriosa para uma reeleição nem tampouco cravar um modelo de comportamento eleitoral. Mas, sabendo que vários autores (BORBA, 2005; BAQUERO, 2000; MANIN, 1995; PALMEIRA e HEREDIA, 2010) apontam para a existência do personalismo político no Brasil - embora não seja o único caso - deseja-se investigar se há um grau maior de apoio quando o mesmo candidato concorre à reeleição, o que estaria em acordo com essa literatura.

A partir de uma amostra de estados a unidade de análise escolhida foi o município. A análise comparativa da proporção de votos foi realizada entre os seguintes pares de eleições: 1998 e 2002, 2002 e 2006 e 2006 e 2010. Procura-se examinar em qual cenário o nível de apoio é maior, estável ou menor, considerando quando é o candidato ou o partido que tentam se reeleger ou quando o partido tenta se manter no poder se inserindo em uma coligação partidária.

\section{O CANDIDATO, O PARTIDO E A COLIGAÇÃO NA ARENA ELEITORAL}

Certamente a competição eleitoral possui no Brasil, além do eleitorado, três atores de relevância: o candidato, o partido e a coligação. Cada um possui determinadas funções na arena política e é de acordo com elas que se pode dizer a sua importância.

Vários países ao redor do mundo, entre eles a Suécia, a Suíça, a Holanda e o Brasil, possuem sistemas políticos conhecidos por estimular o personalismo, em que se atribui grande importância à figura do político permitindo que a intermediação de interesses aconteça por meio dele e não das instituições formais, fazendo valer a política clientelista (PIATTONI, 2001). 
David Samuels denomina os sistemas eleitorais que contribuem para uma política eleitoral individualista de "centrados no candidato" (SAMUELS, 1997). Os políticos, tentado se diferenciar dos demais concorrentes, fazem uma campanha eleitoral focada em sua autoimagem, o que contribui para que o voto dos eleitores, normalmente, signifique uma forma de manifestar apoio pessoal a um candidato e não ao partido, por exemplo (SAMUELS, 1997).

A centralidade no candidato pode ser ampliada também devido a fatores externos às regras dos sistemas eleitorais. Marcello Baquero relaciona o perfil do eleitor personalista à desconfiança e à descrença dos cidadãos nas instituições políticas e na política no geral (BAQUERO, 2000). Além disso, o grande alcance dos meios de comunicação torna próxima e direta a relação entre eleitor e candidato, deixando em segundo plano identidades partidárias ou importância de alianças/coligações políticas (MANIN, 1995).

Sabendo ainda que os interesses dos eleitores estão agregados seja por classe, território ou linhas individuais, o candidato eleito, ao ter nas mãos os recursos a serem por ele alocados, pode escolher que grupos tratar como clientelas e, com isso, sua centralidade se baseia nas negociações em torno da alocação de benefícios políticos, financeiros, materiais, etc., conforme aponta o modelo distributivista (CARVALHO, 2003). O fruto eleitoral disso são escolhas personalistas que fazem surgir um "mercado de votos" (ROCHA \& BARBOSA, 2008). Segundo Barry Ames, “Os políticos não se sustentam como tais cuidando da prosperidade de suas regiões e da provisão de bens públicos, mas distribuindo verbas, serviços e empregos a indivíduos" (AMES, 2003, p. 42).

Contradizendo essa perspectiva, Marcos Bezerra aponta que o político mantém relações mais intensas com as regiões e os municípios onde a sua votação foi mais expressiva, ou seja, localidades que formam suas bases eleitorais (BEZERRA, 1999). Essas regiões, portanto, são visitadas com mais frequência e recebem maior quantidade de recursos (BEZERRA, 1999), o que pode contribuir com a manutenção e ampliação desses redutos eleitorais em benefício do governante. Assim, o voto envolveria um elemento retrospectivo de avaliação dos que estão no poder (NICOLAU, 2006).

Entretanto, a significância dada ao candidato não tira dos partidos políticos o seu papel importante na esfera eleitoral. Os mesmos são responsáveis por estruturar e organizar a competição nas eleições e têm a possibilidade de se colocar em primeiro plano e tomar pra si a tarefa de conquistar votos apelando, por exemplo, para a identificação ideológica dos eleitores ou, e principalmente, para a avaliação retrospectiva do que foi feito em seu governo (SAMUELS, 1997). 
Embora a literatura pessimista sobre partidos no Brasil minimize o papel desses na arena eleitoral, mencionando a alta taxa de volatilidade no país ou a carência ideológica (NICOLAU, 1998; KINZO, 2005), deve-se levar em consideração reflexões como a de Maria do Socorro Braga, que aponta para o fato de que regimes democráticos federais presidencialistas, caracterizados pela difusão do poder nas esferas nacional, estadual e municipal, incentivam a organização dos partidos políticos, visando à conquista de cargos em ambas as esferas (BRAGA, 2009). Dessa forma, incentiva-se também o processo de estruturação dos partidos, o qual segue a estratégia de sobrevivência imposta pelo sistema institucional. Entretanto é evidente que esse argumento não invalida a hipótese de que os eleitores analisam e escolhem considerando prioritariamente as candidaturas individuais, que se tornam o centro das eleições. A cor partidária, nesse caso, parece estar para o eleitor em segundo plano.

No que se refere a alianças políticas, os estímulos para que um partido monte uma coligação a fim de concorrer a uma eleição podem ser vários e a literatura brasileira sobre coligações comumente apresenta dois como os mais relevantes. De um lado, a inserção do partido em uma coligação pode estar ligada a um interesse partidário individual, em que o partido vê a formação de uma aliança partidária como uma estratégia política racional que trará benefícios no contexto eleitoral. De outro, a construção de coligações pode apontar para a manutenção de clãs políticos, "sinalizando aos demais membros do campo político afinidades com determinados grupos e afastamento de outros" (MACHADO \& MIGUEL, 2008, p. 42).

Tendo maior importância nos bastidores da política do que para o eleitorado em si, as coligações não parecem ter influência, a priori, na escolha feita pelo eleitor, tendo em vista a não identificação instantânea do partido ou do candidato, o que dá a impressão da formação de um contexto novo de competição política. Pouca informação é passada ao cidadão sobre as coligações e, por isso, o mesmo não dispõe de uma referência relativa à coligação governista que justifique ou não o seu voto nela. Logicamente, a permanência de um partido no poder por meio da coligação da qual faz parte pode ocorrer, mas ela não poderá ser atribuída, em um primeiro momento, ao partido ou ao candidato que venceu na eleição anterior.

Conforme aponta Bezerra (1999), a identificação das bases eleitorais de um candidato é relevante na medida em que se espera que para elas seja direcionada a maior parte da sua atividade enquanto político. A importância atribuída às bases, no caso do poder executivo estadual vem do fato de que a sua manutenção significa maiores possibilidades de 
conquistar uma reeleição. A verificação da concentração ou da dispersão geográfica da votação no estado para o candidato e/ou partido eleito é importante para identificar as localidades onde ele possui ou não força política.

A espacialidade do voto está, portanto, intimamente relacionada com o grau de apoio que determinado candidato ou partido recebe na região na qual pretende votos para conquistar o cargo eletivo. Verificar como se distribui geograficamente esse apoio é imprescindível para tentar explicar minimamente a (re) eleição. Tal análise se torna ainda mais significativa quando se tem a intenção de fazer comparações entre diferentes cenários em que ocorreu a reeleição, seja quando o candidato ou partido saiu vitorioso ou quando o partido fazendo parte de uma coligação se manteve no poder.

\section{METODOLOGIA DE PESQUISA}

O foco da pesquisa é verificar qual é o grau de apoio que o candidato ou partido reeleito para o cargo de governador tem de uma eleição para outra bem como qual a distribuição dos votos e, por sua vez, desse apoio. Para isso, far-se-á uma análise comparativa entre os cenários de reeleição do candidato, do partido ou da "coligação" que estava no poder. Ressalta-se que quando se fala em reeleição de coligação se considera que o partido que foi eleito na eleição anterior não encabeça uma tentativa à reeleição, mas faz parte da aliança de partidos que formam a coligação vitoriosa na eleição seguinte.

O objeto de estudo consiste na proporção de votos recebida por uma amostra de candidatos, partidos e coligações que foram reeleitos nos estados que comporão uma amostra, considerando o período das quatro últimas eleições - 1998, 2002, 2006 e 2010. A fim de montar a amostra de estados, primeiramente, foram organizados os dados relativos ao cargo de governador nas eleições de 1998, 2002, 2006 e 2010, considerando o candidato vitorioso, seu partido, sua votação percentual, o turno no qual foi eleito e a coligação a qual ele pertencia. Com os dados retirados do site do Tribunal Superior Eleitoral (TSE), isso foi feito para a totalidade dos estados brasileiros mais o Distrito Federal em cada um dos anos eleitorais citados. Ressalta-se que, para fins de organização dos dados e análise, foram utilizados pares de eleições, a saber: 1998-2002; 2002-2006; e, 2006-2010.

Com isso, foi possível observar um quadro geral dos candidatos vitoriosos nas quatro eleições e verificar, por estado, se houve reeleição. A partir disso, elaborou-se uma tabela com todos os estados e o DF contendo o que se denominou de cenários, os quais apontavam para a reeleição ou não de candidato, partido ou coligação. Tomando como base 
sempre a eleição anterior nos três pares de eleições considerados, foi atribuído, por estado, um cenário por ano eleitoral (Quadro 1).

Observaram-se cenários de reeleição de partido e candidato ${ }^{3}$, candidato, partido e coligação bem como cenários em que houve a não reeleição de partido e candidato e a não reeleição de partido. Além disso, cenários em que o partido não encabeçou uma candidatura, mas estava coligado e em que nem o partido nem o candidato tentaram reeleição.

\begin{tabular}{|c|c|c|c|c|}
\hline \multicolumn{5}{|c|}{ Quadro 1 - Cenários de reeleição de candidato, partido e coligação, por estado. } \\
\hline ESTADO & $\begin{array}{c}\text { ELEIÇÃO } \\
\text { 1998/PAR } \\
\text { TIDO }\end{array}$ & ELEIÇÃO 2002 & ELEIÇÃO 2006 & ELEIÇÃO 2010 \\
\hline Acre & PT & Partido e candidato & Partido & Partido \\
\hline Alagoas & PSB & Partido e candidato & $\begin{array}{l}\text { Não se candidatou } \\
\text { (partido e candidato) }\end{array}$ & Partido e candidato \\
\hline Amapá & PSB & $\begin{array}{l}\text { Não reeleito } \\
\text { (partido) }\end{array}$ & Partido e candidato & $\begin{array}{l}\text { Não se candidatou, } \\
\text { mas estava coligado }\end{array}$ \\
\hline Amazonas & PFL & Coligação & $\begin{array}{l}\text { Não se candidatou, } \\
\text { mas estava coligado }\end{array}$ & Coligação \\
\hline Bahia & PFL & Partido & $\begin{array}{l}\text { Não reeleito (partido e } \\
\text { candidato) }\end{array}$ & Partido e candidato \\
\hline Ceará & PSDB & Partido & $\begin{array}{l}\text { Não reeleito (partido e } \\
\text { candidato) }\end{array}$ & Partido e candidato \\
\hline $\begin{array}{l}\text { Distrito } \\
\text { Federal }\end{array}$ & PMDB & Partido e candidato & $\begin{array}{l}\text { Não se candidatou, } \\
\text { mas estava coligado }\end{array}$ & $\begin{array}{l}\text { Não se candidatou, } \\
\text { mas estava coligado }\end{array}$ \\
\hline $\begin{array}{l}\text { Espírito } \\
\text { Santo }\end{array}$ & PSDB & $\begin{array}{l}\text { Não reeleito } \\
\text { (partido) }\end{array}$ & Candidato & Coligação \\
\hline Goiás & PSDB & Partido e candidato & Coligação & Candidato \\
\hline Maranhão & PFL & Partido & Não reeleito (partido) & Candidato \\
\hline $\begin{array}{l}\text { Mato } \\
\text { Grosso }\end{array}$ & PSDB & $\begin{array}{l}\text { Não reeleito } \\
\text { (partido) }\end{array}$ & Partido e candidato & Coligação \\
\hline $\begin{array}{l}\text { Mato } \\
\text { Grosso do } \\
\text { Sul }\end{array}$ & PT & Partido e candidato & Não reeleito (partido) & Partido e candidato \\
\hline $\begin{array}{l}\text { Minas } \\
\text { Gerais }\end{array}$ & PMDB & $\begin{array}{l}\text { Não reeleito } \\
\text { (partido) }\end{array}$ & Partido e candidato & Partido \\
\hline Pará & PSDB & Partido & Não reeleito (partido) & Não reeleito (partido) \\
\hline Paraíba & PMDB & $\begin{array}{l}\text { Não reeleito } \\
\text { (partido) }\end{array}$ & Partido e candidato & Coligação \\
\hline Paraná & PFL & $\begin{array}{l}\text { Não se candidatou, } \\
\text { mas estava coligado }\end{array}$ & Partido e candidato & $\begin{array}{l}\text { Não se candidatou, } \\
\text { mas estava coligado }\end{array}$ \\
\hline $\begin{array}{c}\text { Pernambuc } \\
\text { o }\end{array}$ & PMDB & Partido e candidato & $\begin{array}{l}\text { Não se candidatou, } \\
\text { mas estava coligado }\end{array}$ & Partido e candidato \\
\hline Piauí & PFL & $\begin{array}{c}\text { Não reeleito (partido } \\
\text { e candidato) }\end{array}$ & Partido e candidato & Coligação \\
\hline $\begin{array}{l}\text { Rio de } \\
\text { Janeiro }\end{array}$ & PDT & $\begin{array}{l}\text { Não reeleito } \\
\text { (partido) }\end{array}$ & $\begin{array}{l}\text { Não se candidatou, } \\
\text { mas estava coligado }\end{array}$ & Partido e candidato \\
\hline $\begin{array}{l}\text { Rio Grande } \\
\text { do Norte }\end{array}$ & PMDB & $\begin{array}{l}\text { Não se candidatou, } \\
\text { mas estava coligado }\end{array}$ & Partido e candidato & Não reeleito (partido) \\
\hline
\end{tabular}

\footnotetext{
${ }^{3}$ No caso em que partido e candidato foram reeleitos, priorizou-se o candidato no cenário de reeleição.
} 


\begin{tabular}{|c|c|c|c|c|}
\hline $\begin{array}{l}\text { Rio Grande } \\
\text { do Sul }\end{array}$ & PT & $\begin{array}{l}\text { Não reeleito } \\
\text { (partido) }\end{array}$ & $\begin{array}{l}\text { Não reeleito (partido e } \\
\text { candidato) }\end{array}$ & $\begin{array}{c}\text { Não reeleito (partido } \\
\text { e candidato) }\end{array}$ \\
\hline Rondônia & PFL & $\begin{array}{l}\text { Não reeleito (partido } \\
\text { e candidato) }\end{array}$ & Candidato & Não reeleito (partido) \\
\hline Roraima & PPB & $\begin{array}{l}\text { Não se candidatou, } \\
\text { mas estava coligado }\end{array}$ & $\begin{array}{l}\text { Não se candidatou } \\
\text { (partido e candidato) }\end{array}$ & Partido \\
\hline $\begin{array}{c}\text { Santa } \\
\text { Catarina }\end{array}$ & PPB & $\begin{array}{l}\text { Não reeleito (partido } \\
\text { e candidato) }\end{array}$ & Partido e candidato & Coligação \\
\hline São Paulo & PSDB & Partido & Partido & Partido \\
\hline Sergipe & PSDB & $\begin{array}{l}\text { Não se candidatou, } \\
\text { mas estava coligado }\end{array}$ & $\begin{array}{l}\text { Não reeleito (partido e } \\
\text { candidato) }\end{array}$ & Partido e candidato \\
\hline Tocantins & PFL & Partido & Candidato & Não reeleito (partido) \\
\hline
\end{tabular}

Fonte: Elaboração da autora a partir dos dados do TSE <www.tse.jus.br>

Somando-se o objetivo do estudo com a existência na arena eleitoral de três atores políticos - candidato, partido e coligação foi composta a amostra de estados. Esses foram escolhidos tendo em vista os cenários referentes à reeleição, priorizando os estados com maior número de municípios, visto que quanto maior o número de municípios maior a possibilidade de se verificar a dinâmica geográfico-eleitoral no estado. A tabela 1 mostra os estados e as eleições que foram selecionados para compor a amostra dos cenários de reeleição de candidato, partido e coligação.

\begin{tabular}{|c|c|c|c|c|c|c|}
\hline \multirow{8}{*}{$\begin{array}{c}\text { Cenário } \\
\text { - } \\
\text { reeleição }\end{array}$} & \multicolumn{2}{|c|}{ CANDIDATO } & \multicolumn{2}{|c|}{ PARTIDO } & \multicolumn{2}{|c|}{ COLIGAÇÃO } \\
\hline & Estado & Eleição & Estado & Eleição & Estado & Eleição \\
\hline & Alagoas & 1998-2002 & Bahia & $1998-2002$ & Amazonas & $1998-2002$ \\
\hline & Bahia & $2006-2010$ & Ceará & $1998-2002$ & Espírito Santo & $2006-2010$ \\
\hline & Ceará & $2006-2010$ & Maranhão & $1998-2002$ & Goiás & $2002-2006$ \\
\hline & Goiás & 1998-2002 & Minas Gerais & 2006-2010 & Paraíba & $2006-2010$ \\
\hline & Pernambuco & 1998-2002 & São Paulo & 1998-2002 & Piauí & $2006-2010$ \\
\hline & Pernambuco & $2006-2010$ & São Paulo & 2006-2010 & Santa Catarina & $2006-2010$ \\
\hline
\end{tabular}

O próximo passo foi extrair do site do TSE as votações por município relativas aos estados selecionados. Conforme observado, para cada estado foram analisadas as votações de um par de eleições referente à reeleição de candidato, partido ou coligação. A porcentagem de votos por município do candidato, partido ou coligação vitorioso foi utilizada como unidade de análise e o resultado da comparação entre as distribuições de votos das duas eleições consideradas foi conseguido pela diferença entre a porcentagem de votos em um município de uma eleição e a anterior.

$$
\operatorname{Dif}(\text { votmun })=\% \operatorname{Vot}(\text { eleição t })-\% \operatorname{Vot}(\text { eleição t-4 })
$$


Desse modo, por meio dos valores da diferença entre as votações, foi possível notar se nos municípios que compunham um estado havia um aumento, uma diminuição ou ainda uma estabilidade da votação de uma eleição para outra.

A classificação dos valores que iriam ser considerados como aumento, diminuição ou estabilidade da votação entre duas eleições nos municípios do estado analisado, foi feita a partir da escala construída na legenda dos mapas de quartil que foram elaborados. A escala considerou como valores de diminuição (negativos) aqueles entre -50 a -5 pontos percentuais, localizados no primeiro quartil; como valores de estabilidade (central) aqueles entre $-4,9$ a 5 pontos percentuais dispostos no segundo quartil; e, como valores de aumento (positivos) aqueles entre 5,1 a 50 pontos percentuais, que compunham o terceiro quartil.

\section{DISTRIBUIÇÃO DA VOTAÇÃO PARA O CARGO DE GOVERNADOR NOS MUNICÍPIOS NO CASO DE REELEIÇÃO}

\subsection{Resultados quantitativos para a reeleição do candidato}

Os dados referentes à reeleição do candidato nos estados (tabela 2) são claros quanto ao crescimento da votação no candidato governista na maioria dos municípios de uma eleição para outra.

Tabela 2 - Disposição percentual dos municípios em torno da variação da votação observada no cenário de reeleição de candidato nos estados selecionados

\begin{tabular}{c|c|c|c|c|c|c}
\hline \multicolumn{7}{c}{ Candidato - reeleito } \\
\hline Eleições & $1998-2002$ & $1998-2002$ & $2006-2010$ & $2006-2010$ & $2006-2010$ & $1998-2002$ \\
\hline UF & Goiás & Alagoas & Pernambuco & Bahia & Ceará & Pernambuco \\
\hline Positivo & $45,12 \%$ & $48,04 \%$ & $89,19 \%$ & $77,22 \%$ & $28,26 \%$ & $69,19 \%$ \\
\hline Central & $36,18 \%$ & $23,53 \%$ & $10,27 \%$ & $14,87 \%$ & $17,39 \%$ & $18,92 \%$ \\
\hline Negativo & $18,70 \%$ & $28,43 \%$ & $0,54 \%$ & $7,91 \%$ & $54,35 \%$ & $11,89 \%$ \\
\hline
\end{tabular}

Embora não possam ser feitas generalizações, os dados amostrais indicam que o sucesso de reeleição quando o partido lança o candidato que foi vitorioso na eleição anterior é significativamente positivo, o que corrobora com a literatura acerca da preponderância do voto personalista no Brasil. Essa ideia se torna ainda mais evidente quando se analisam os dados relativos à reeleição do partido governista quando ele lança uma candidatura diferente da eleição anterior. 
O Ceará no par de eleições 2006-2010 é o único caso da amostra que não segue o padrão observado. Embora o candidato governista tenha sido reeleito, a porcentagem de municípios onde decresceu a votação de uma eleição para outra foi alta quando comparada às porcentagens dos municípios onde a votação aumentou ou permaneceu estável. Não obstante a retração da base eleitoral nesse caso, uma possível explicação para a reeleição do candidato governista pode ser encontrada quando se analisa o tamanho populacional dos municípios cearenses onde a votação foi positiva e negativa. A hipótese é de que a votação decresceu nos municípios de baixa população, aumentando ou permanecendo estável, no entanto, nos municípios mais populosos.

\subsection{Resultados quantitativos para a reeleição do partido}

$\mathrm{Na}$ tabela 3, observa-se que na maioria dos municípios em que o partido do governo estadual tentou reeleição com outra candidatura houve um decréscimo na votação. Em mais de 50\% dos municípios dos estados do Ceará, Maranhão, Bahia, São Paulo (2006-2010) e Minas Gerais houve queda na votação para o partido. Novamente, a hipótese é que a explicação para a reeleição do partido mesmo com diminuição da votação na maioria dos municípios esteja no tamanho populacional daqueles onde a votação cresceu ou ficou estável.

\begin{tabular}{|c|c|c|c|c|c|c|}
\hline \multicolumn{7}{|c|}{ Partido - reeleito } \\
\hline Eleições & 1998-2002 & 1998-2002 & 1998-2002 & 2006-2010 & 1998-2002 & 2006-2010 \\
\hline UF & Ceará & Maranhão & Bahia & São Paulo & São Paulo & Minas Gerais \\
\hline Positivo & $19,02 \%$ & $3,69 \%$ & $4,32 \%$ & $1,40 \%$ & $40,00 \%$ & $2,81 \%$ \\
\hline Central & $17,93 \%$ & $15,21 \%$ & $22,54 \%$ & $16,74 \%$ & $20,00 \%$ & $14,30 \%$ \\
\hline Negativo & $63,04 \%$ & $81,11 \%$ & $73,14 \%$ & $81,86 \%$ & $40,00 \%$ & $82,88 \%$ \\
\hline
\end{tabular}

O único caso que destoa dos demais é São Paulo entre as eleições de 1998 e 2002, em que, curiosamente, houve votação positiva e negativa na mesma porcentagem de municípios. Conforme será indicado a seguir a partir da comparação dos mapas das votações nos dois períodos eleitorais, nesse caso em particular, ao que parece, ocorreu uma inversão significativa das bases eleitorais do partido, isto é, onde o partido tinha baixa votação passou a ter votação expressiva e vice-versa.

A porcentagem de municípios que permaneceram estáveis (centrais) quanto à votação entre uma eleição e outra, tanto no caso da reeleição do candidato quanto da reeleição do partido, quando olhada por si só, não se mostrou um dado importante para a 
manutenção no poder do candidato ou do partido. Em todos os casos nos dois conjuntos de dados (candidato e partido) a porcentagem de municípios que apresentaram certa estabilidade na votação ficou abaixo dos 37\%. No entanto, a porcentagem dos municípios estáveis seja relevante quando analisada tendo em vista o tamanho da população dos municípios em questão. Como já explicitado, a estabilidade observada nos municípios populosos pode ajudar na explicação da reeleição do candidato ou do partido nos estados onde a votação foi negativa na maior parte dos municípios.

Com efeito, a disposição percentual dos municípios em torno da variação da votação nos casos em que houve a reeleição do candidato e naqueles em que ouve a reeleição do partido mostra a tendência do eleitor brasileiro em votar considerando a figura do candidato, deixando em segundo plano as referências partidárias. Infere-se que há maior possibilidade de sucesso na manutenção do poder executivo estadual quando o partido lança a mesma candidatura do que quando ele indica outra pessoa para o cargo de governador.

Confiar na manutenção das bases eleitorais de uma eleição para a seguinte quando o partido tenta a reeleição se mostra muito arriscado para garantir a vitória, mesmo que o governo procure mantê-las por meio de transferências financeiras, aproximações com os prefeitos municipais e demais líderes locais ou outros incentivos. Desse modo, faz-se necessário procurar ampliar a votação, o que, de acordo com os dados da amostra, é mais propício quando o mesmo candidato concorre à reeleição.

\subsection{Resultados quantitativos para a reeleição do partido inserido em uma coligação}

A tabela 4, que mostra resultados amostrais da manutenção do partido no poder por meio de uma coligação, diferentemente das tabelas 1 e 2, não apresenta padrões.

\begin{tabular}{|c|c|c|c|c|c|c|}
\hline \multicolumn{7}{|c|}{ Partido-coligação - reeleito } \\
\hline Eleições & $2006-2010$ & $2006-2010$ & 1998-2002 & $2006-2010$ & $2002-2006$ & $2006-2010$ \\
\hline UF & Paraíba & Piauí & Amazonas & Santa Catarina & Goiás & Espírito Santo \\
\hline Positivo & $21,24 \%$ & $45,54 \%$ & $67,74 \%$ & $18,09 \%$ & $47,56 \%$ & $12,82 \%$ \\
\hline Central & $36,73 \%$ & $28,13 \%$ & $22,58 \%$ & $41,64 \%$ & $39,84 \%$ & $60,26 \%$ \\
\hline Negativo & $42,04 \%$ & $26,34 \%$ & $9,68 \%$ & $40,27 \%$ & $12,60 \%$ & $26,92 \%$ \\
\hline
\end{tabular}

Dos estados que compunham a amostra, Piauí, Amazonas e Goiás tiveram na maioria dos municípios uma expansão da votação, ao passo que a Paraíba apresentou um 
cenário expressivo de votação negativa de uma eleição para outra. Já Santa Catarina e Espírito Santo, nas eleições consideradas, tiveram um maior número de municípios que permaneceram estáveis quanto à votação na coligação em comparação com a votação que tinha tido o partido em um ano eleitoral anterior.

Sabendo da escassez de estudos no Brasil sobre a influência que coligações políticas têm no comportamento dos eleitores, os dados empíricos encontrados por esse estudo sustentam essa lacuna na literatura, de modo que não é possível observar se a dinâmica de coligações contribui ou não para a manutenção de bases eleitorais. Talvez estudos mais aprofundados sobre coligações, os quais envolvam outras variáveis do cenário políticoeleitoral, tenham maior sucesso em desvendar se há e qual é a contribuição das mesmas para a escolha do voto pelo eleitorado.

\section{DISTRIBUIÇÃO GEOGRÁFICA DA DIFERENÇA DA VOTAÇÃO ENTRE ELEIÇÕES NAS SITUAÇÕES DE REELEIÇÃO DO CANDIDATO, DO PARTIDO E DO PARTIDO INSERIDO EM COLIGAÇÃO}

Para os fins deste estudo, será considerada apenas a dimensão horizontal da geografia dos votos, que consiste na proximidade ou no distanciamento das localidades onde houve votação significativa. No entanto, ressalta-se que os dados da pesquisa aqui realizada não tratam da observância dos municípios onde o candidato ou o partido tiveram maioria de votos, mas tratam da variação da proporção de votos para esses de uma eleição para outra.

Considerando o vetor concentração, pode-se falar que a votação é concentrada ou dispersa. A primeira é o caso em que um candidato ou partido tem votação expressiva em um grupo de municípios próximos. Já a votação dispersa é aquela em que os municípios onde se teve votação significativa são espalhados pelo estado. Conforme apontam Soares e Terron (2008), o padrão espacial de uma votação dispersa é semelhante à figura de um mosaico, em que não existem territorialmente muitas regiões homogêneas em relação à escolha eleitoral.

Além dos fatores concentração e dispersão, a análise dos mapas levou em consideração a localização geográfica capital-interior, conforme discursão teórica feita anteriormente. Nos mapas, a capital dos estados selecionados está identificada com um ponto de cor preta.

Os mapas dispostos nas páginas seguintes indicam a diferença de votação entre duas eleições no caso de reeleição do candidato, do partido ou da coligação a qual o partido vitorioso na última eleição pertencia. O intuito é verificar qual é a dinâmica espacial dos votos para essas três situações de reeleição e se há alguma diferença entre elas. Para que as 
comparações da distribuição territorial do eleitorado entre esses três cenários sejam observadas com mais facilidade, os mapas foram organizados em três conjuntos, tendo em vista as três situações de reeleições já citadas.

\subsection{Diferença da votação considerando a reeleição do candidato}

Tendo em vista os mapas dos estados selecionados para verificar a dinâmica geográfica da reeleição do candidato, dispostos a seguir, observa-se que em três dos quatro casos analisados se tem dispersão da diferença positiva de votação. A exceção é o estado do Ceará, conforme citado anteriormente. Comparando-se os mapas entre si, percebe-se que alguns estados demonstram maior dispersão na proporção de votos de uma eleição para outra do que os demais. Olhando os mapas individualmente, à exceção do Ceará, as diferenças de votação observadas ao candidato reeleito são dispersas e em sua maioria se concentram no segundo e no terceiro quartis, que representam valores positivos.

\section{Mapa 1: Diferença de votação para o cargo de governador, por município - GO (1998-2002)}

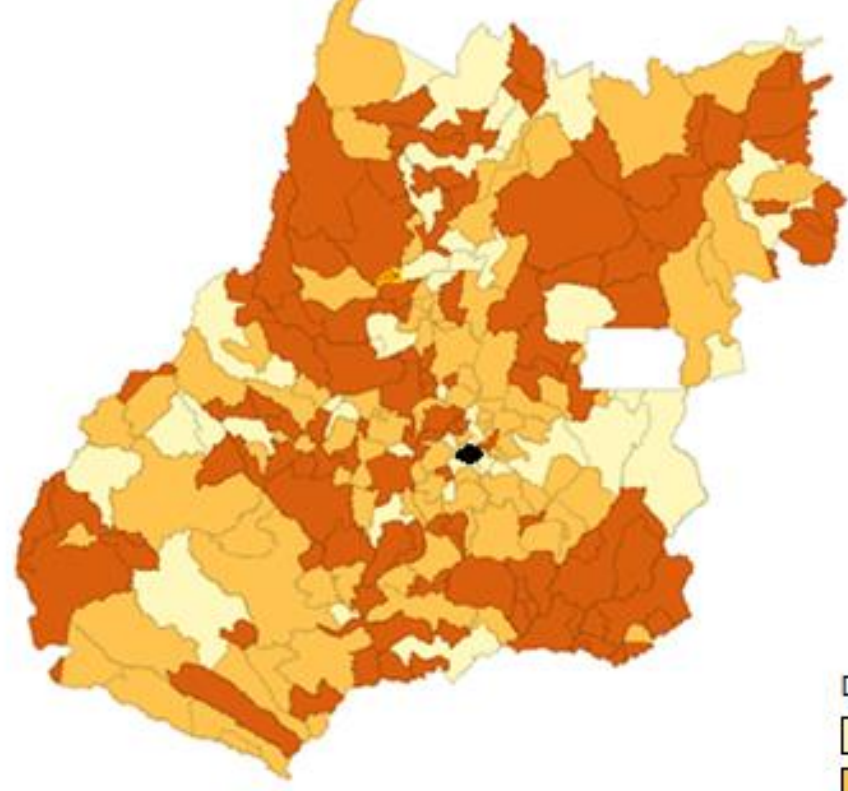

Fonte: Elaboração da autora
Diferença Goiás 1998_2002

-50 a $-5(45)$

$-4,9$ a $5(90)$

5,1 a $50(111)$ 
Mapa 2: Diferença de votação para o cargo de governador, por município - PE (2006-2010)

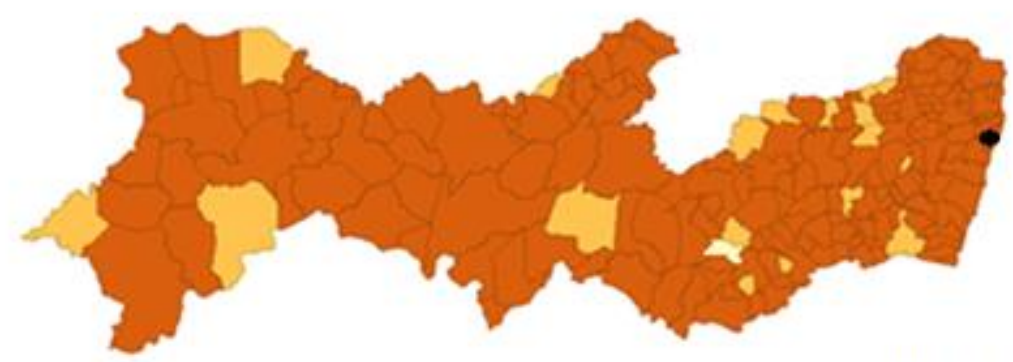

Diferença Pernambuco 2006-2010

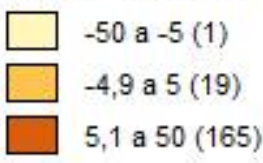

Fonte: Elaboração da autora

Mapa3: Diferença de votação para o cargo de governador, por município - BA (2006-2010)

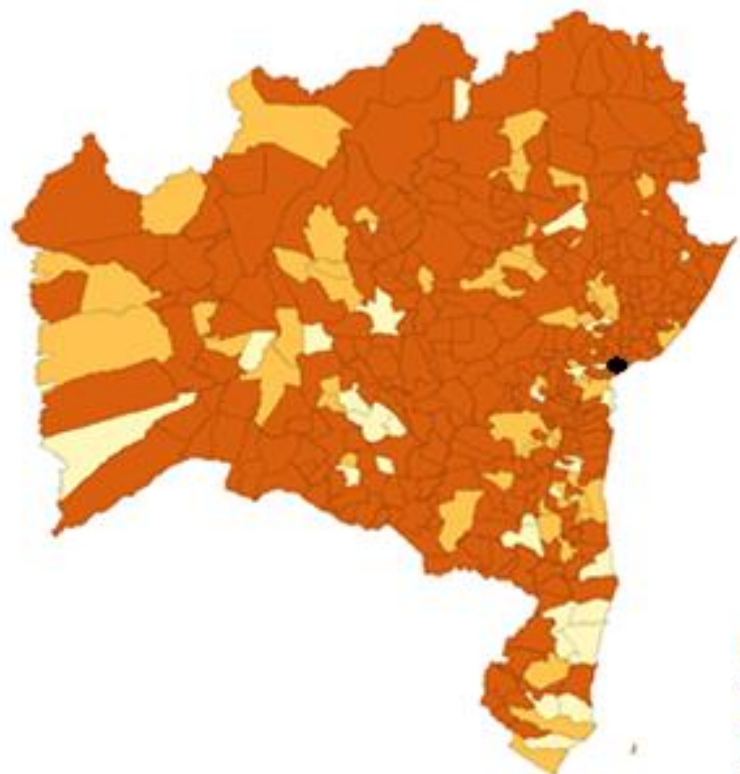

Diferença Bahia 2006-2010

Fonte: Elaboração da autora

$\square-50$ a $-5(33)$
$\square-4,9$ a $5(62)$
5,1 a $50(322)$ 
Mapa 4: Diferença de votação para o cargo de governador, por município - CE (2006-2010)

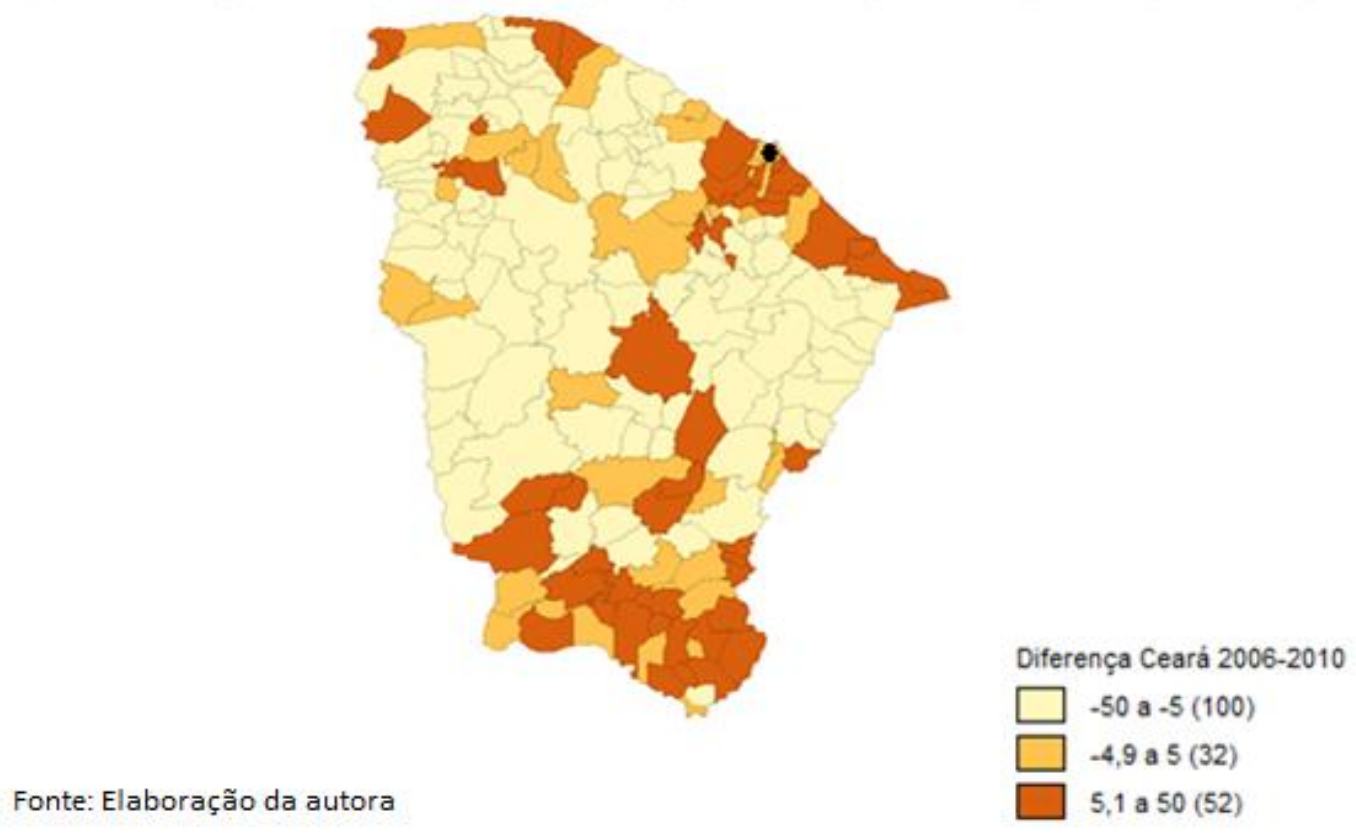

Esses dados corroboram com a literatura que vê o sistema político-eleitoral brasileiro como personalista no sentido dar maior relevância ao candidato nas campanhas eleitorais em detrimento dos partidos políticos e mais ainda das coligações partidárias. $O$ voto dos eleitores, portanto, é direcionado ao candidato, o que evidencia um comportamento eleitoral pautado no apoio pessoal do eleitor ao político, deixando em segundo plano fatores mais gerais que podem influenciar o voto como ideologia partidária, políticas pragmáticas, entre outros. Nos estudos de caso realizados, a dispersão observada na reeleição do candidato indica que o partido tem maiores chances de se manter no poder quando lança a mesma candidatura da eleição anterior, de modo que, como mostram os dados, o candidato amplia sua votação por todo o estado e recebe o apoio de grande parte da população.

\subsection{Diferença da votação considerando a reeleição do partido}

Observando-se os quatro mapas relativos à reeleição do partido, dispostos abaixo, tem-se que à exceção de São Paulo entre 1998-2002, os demais estados mostram que a diferença positiva de votação quando o partido tenta a reeleição sem lançar a mesma candidatura da eleição anterior é concentrada em certas regiões dos estados, diferentemente do que acontece com distribuição geográfica observada na reeleição do candidato. Novamente, a comparação dos mapas entre si pode fazer com que algumas distribuições sejam mais concentradas que outras. No entanto, sendo o objetivo identificar padrões a partir 
dos estudos de casos selecionados, tem-se que a concentração geográfica da diferença positiva de votação consiste em uma característica da reeleição do partido político.

\section{Mapa 5: Diferença de votação para o cargo de governador, por município - BA (1998-2002)}

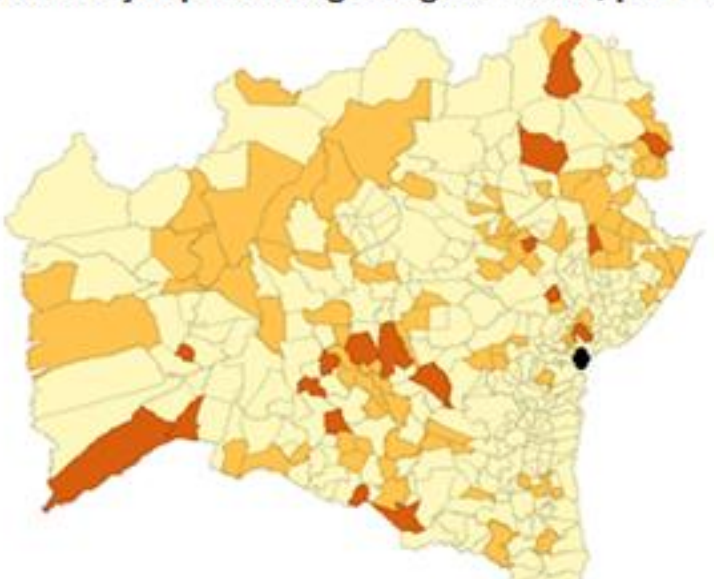

Fonte: Elaboração da autora

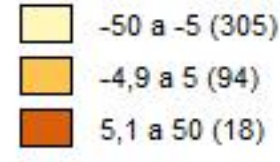

Mapa 6 : Diferença de votação para o cargo de governador, por município - SP (1998-2002)

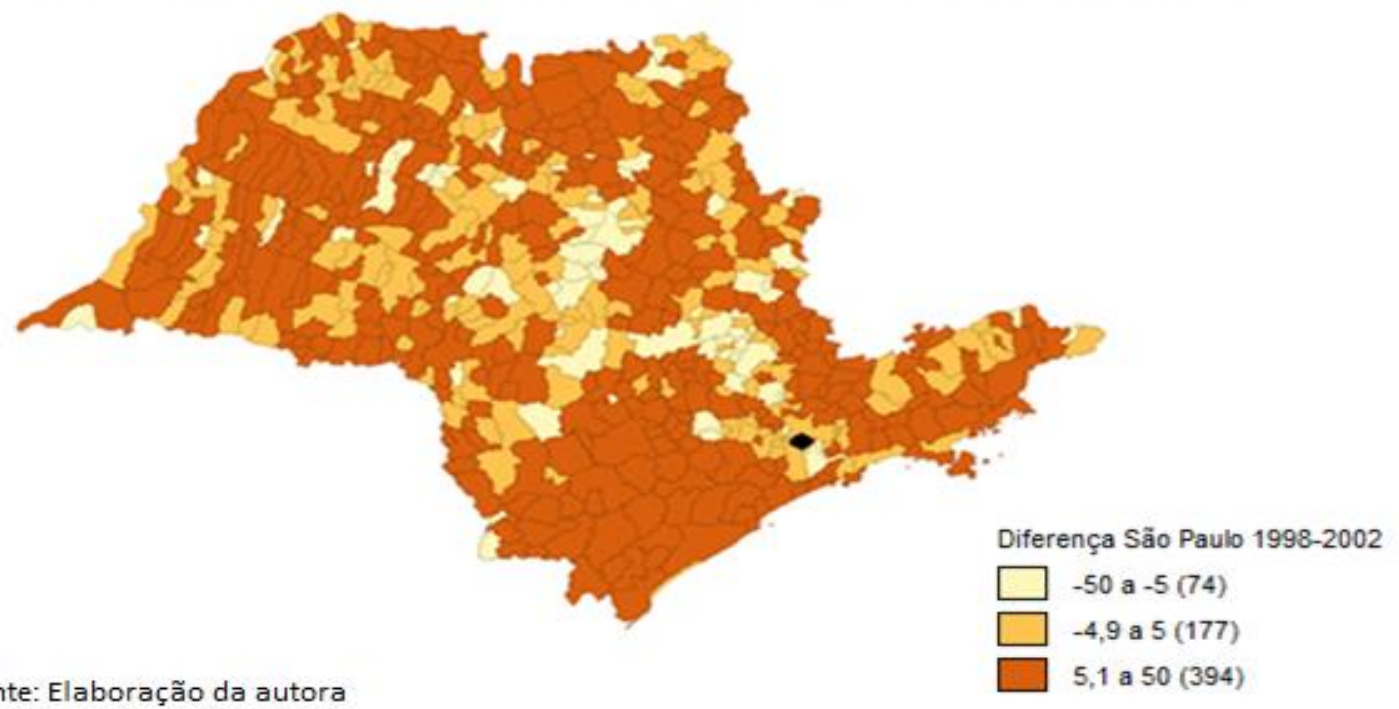

Fonte: Elaboração da autora 
Mapa 7 : Diferença de votação para o cargo de governador, por municipio - SP (2006-2010)

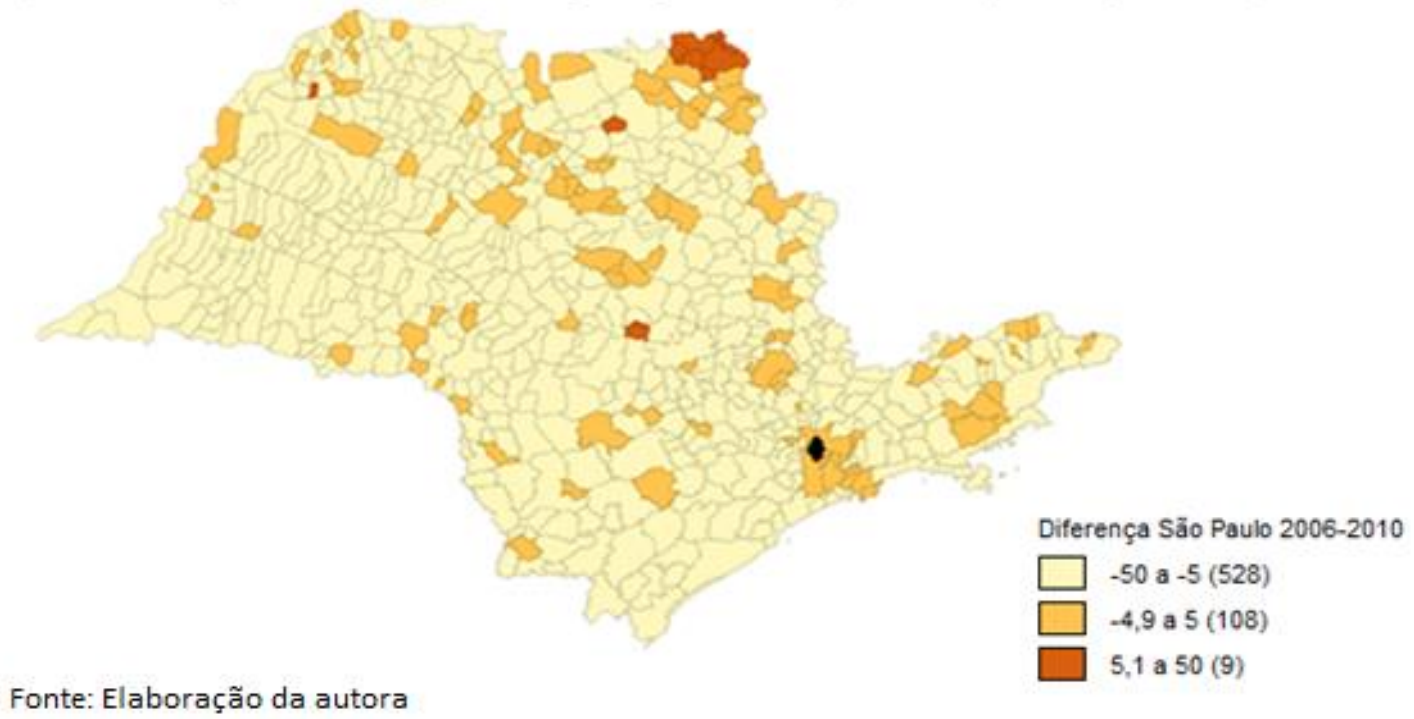

Mapa 8 : Diferença de votação para o cargo de governador, por município - MG (2006-2010)

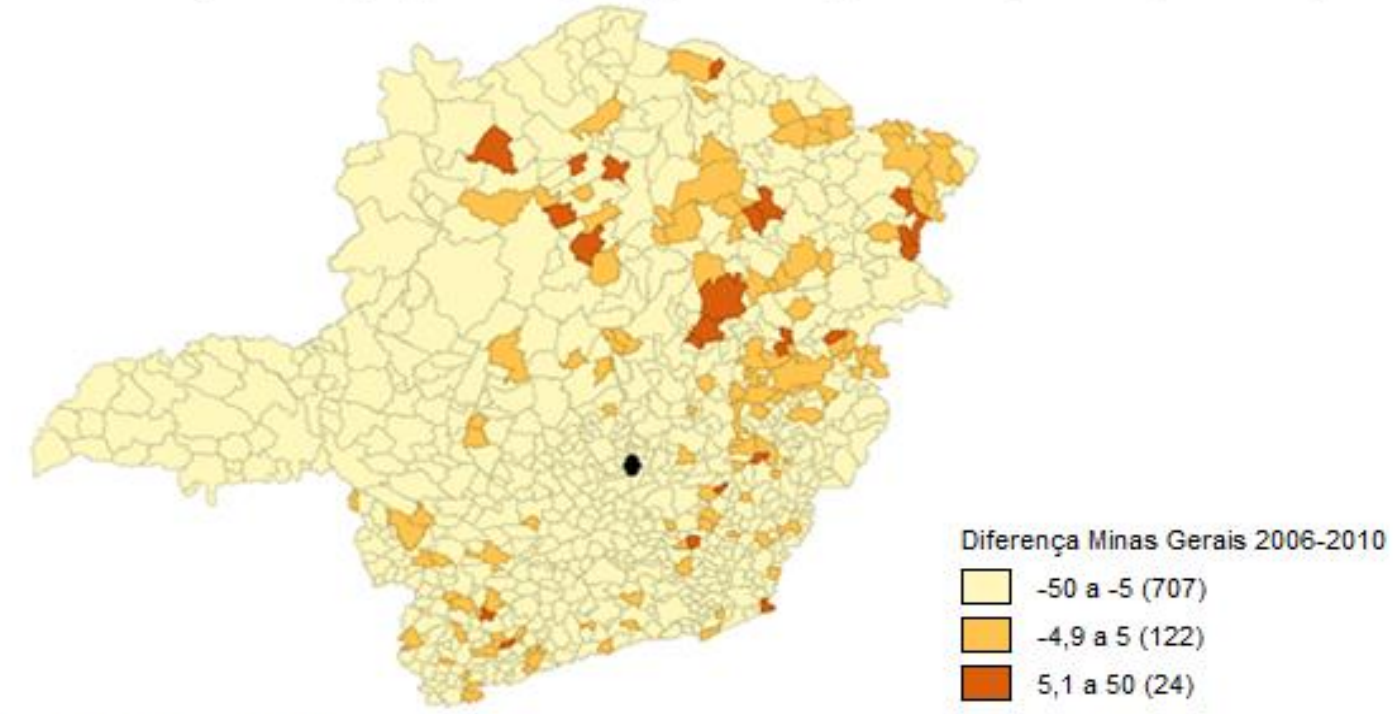

Fonte: Elaboração da autora

Embora esse apontamento não possa ser generalizado para todas as situações em que o partido tenta se manter no poder, os dados encontrados vão de encontro à literatura, que evidencia a fragilidade dos partidos políticos na arena eleitoral em comparação à figura do candidato. Enquanto o voto personalista exalta a força política do candidato, maximizando o seu apoio eleitoral e consequentemente suas bases eleitorais, a permanência do voto no partido ocorre em regiões específicas, concentradas nos estados, demonstrando que a ideologia ou a avaliação retrospectiva do governo como direcionamento do comportamento eleitoral do cidadão são fatores, na maioria das vezes, secundários na escolha do voto. 


\subsection{Diferença da votação considerando a reeleição do partido a partir da sua inserção em uma coligação partidária}

Nos mapas abaixo referentes à permanência do partido no poder através da vitória da coligação à qual ele pertencia, nota-se que é difícil estabelecer um padrão geográfico de distribuição da diferença da votação, assim como não é possível falar em padrão quando se analisam os dados quantitativos da distribuição de municípios referentes a esse cenário de "reeleição". O estado do Amazonas apresenta uma concentração da diferença negativa. Já o estado do Piauí apresenta uma dispersão da diferença positiva. Os mapas, nesse caso, são mais relevantes para se analisar a distribuição geográfica da diferença da votação de cada estado, levando em conta suas particularidades. O papel das coligações partidárias na arena eleitoral ainda merece atenção e requer estudos mais minuciosos a fim de, pelo menos, minimizar a escassez da literatura existente sobre esse tema.

Mapa 9 : Diferença de votação para o cargo de governador, por municipio - AM (1998-2002)

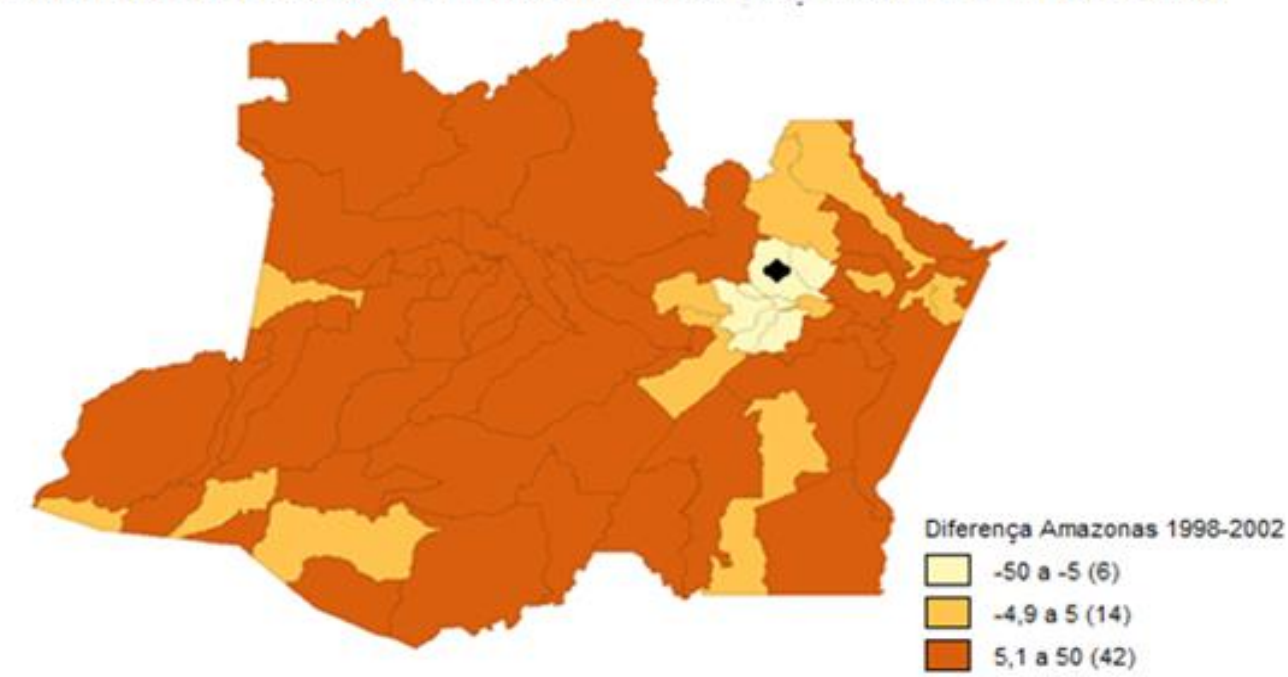

Fonte: Elaboração da autora 

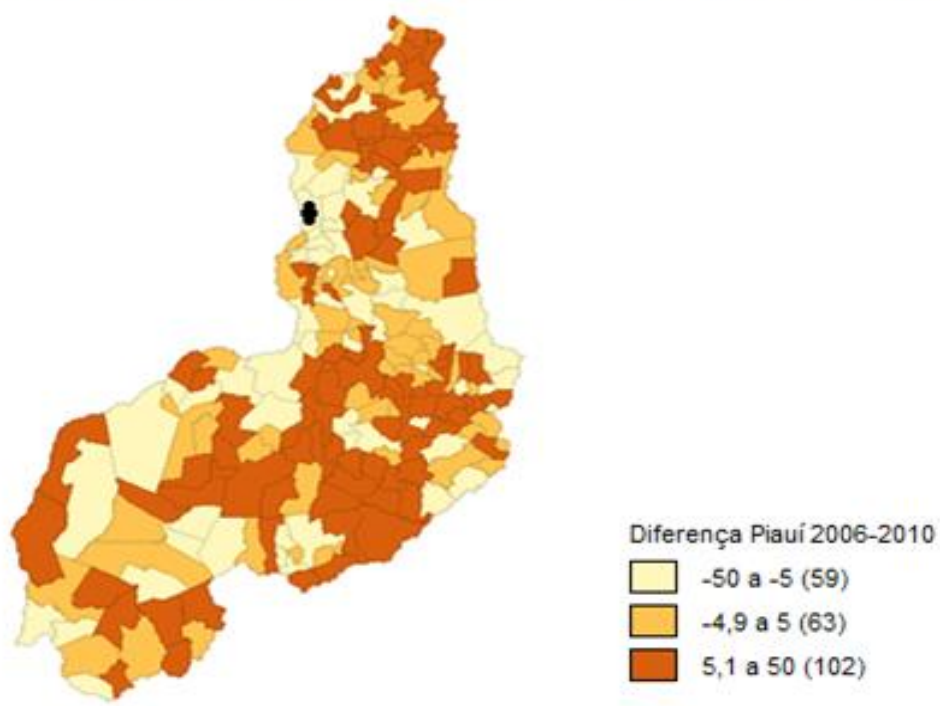

Fonte: Elaboração da autora

\section{CONSIDERAÇÕES FINAIS}

Embora não possam ser feitas generalizações, os dados dos estudos de casos indicam que o sucesso de reeleição quando o partido lança o candidato que foi vitorioso na eleição anterior é significativamente positivo, o que corrobora com a literatura acerca da preponderância do voto personalista no Brasil. Já quando o partido tenta a reeleição, mas não lança a mesma candidatura, há significante decréscimo na votação recebida pelo novo candidato na maioria dos municípios dos estados analisados, de modo que a sua vitória pode ser explicada pelo tamanho dos municípios onde a votação foi expressiva. No caso da manutenção do partido no poder através de coligações, não é possível observar padrões de aumento ou diminuição da proporção de votos entre dois períodos eleitorais. Nesse sentido, a relevância das coligações no comportamento do eleitorado ainda é uma incógnita.

A análise cartográfica a partir dos vetores de concentração e dispersão da votação indica que, embora não possam ser feitas generalizações, podemos falar em estadualização dos votos quando há a reeleição do candidato, tendo em vista que se verifica em municípios dispersos por todo o estado o crescimento da proporção de votos recebida em uma eleição em comparação com a anterior. Ao passo que na reeleição do partido há certa municipalização dos votos favoráveis, de forma que o aumento da proporção de votos ocorre em municípios concentrados em regiões específicas do estado. Novamente, não é possível descrever padrões no caso da manutenção do partido inserido na coligação que foi vitoriosa. 


\section{REFERÊNCIAS}

ABRUCIO, F. L. 1994. “Os barões da federação”. Lua Nova [online], n.33, pp. 165-183.

ALMEIDA, A.; LOPEZ, F. 2012. "Legisladores, captadores e assistencialistas: a representação política no nível local". Instituto de Pesquisa Econômica Aplicada, Brasília/Rio de Janeiro.

AMES, B. 2003. Os entraves da democracia no Brasil. Rio de Janeiro: Editora FGV.

ARON, R. 1985. "Reflexões Sobre a Política e a Ciência Política Francesas" (p. 321 a 334). In: Aron, R. Estudos Políticos, $2^{a}$ ed., Brasília, Ed. UnB, Coleção Pensamento Político.

BEZERRA, M. O. 1999. Em nome das "bases": política, favor e dependência pessoal. Rio de Janeiro: Relume-Dumará - NUAP.

BORGES, FERNANDES \& FILHO. 2010. "Repensando a Política Estadual: Competição vertical, políticas sociais e mudança política nos estados brasileiros". Relatório de projeto de pesquisa - Edital Universal do CNPq - 2007. Natal/Brasília.

BRAGA, M. do S. S. \& BOURDOUKAN, A. 2009. "Partidos Políticos no Brasil: Organização Partidária, Competição Eleitoral e Financiamento Público". Perspectivas, São Paulo, v. 35, p. 117-148, jan./jun.

CARVALHO, N. R. de. 2003. E no início eram as bases: geografia política do voto e comportamento legislativo no Brasil. Rio de Janeiro: Revan.

CONVERSE, P. E. 1964. "The Nature of Belief Systems in Mass Publics”. In: APTER, D. E. Ideology and Discontent. New York: Free Press of Glencoe, p. 206-261.

FERRAZ, S. E. 2009. “Voto e Classe: notas sobre alguns estudos recentes”. Opinião Pública, Campinas, v. 15, n. 2, Nov.

KINZO, M. D’Alva. “Os partidos no eleitorado: percepções públicos e laços partidários no Brasil”. Revista Brasileira de Ciências Sociais, vol. 20, n 57, fevereiro.

LAMOUNIER, B. 1978. “Comportamento Eleitoral em São Paulo: passado e presente”. In: CARDOSO, F. H., comp. Partidos políticos e eleições no Brasil. Rio de Janeiro, Paz e Terra, $2^{\mathrm{a}}$ ed., $262 \mathrm{p}$.

LAZARSFELD, P.; BERELSON, B. \& GAUDET, H. 1970. "The nature of personal influence". New York: Columbia University Press, p. 150-158.

MACHADO, C. M. \& MIGUEL, 2008. L. F. "Padrões de coesão e dispersão: Uma proposta de tipologia para coligações”. Teoria \& Pesquisa, vol. 20, n 2. São Carlos, pp. 37-58.

MANIN, B. 1995. “As metamorfoses do governo representativo”. Revista Brasileira de Ciências Sociais, ano 10, n. 29. 
NICOLAU, J. 2006. "O sistema eleitoral de lista aberta no Brasil". Dados [online], vol.49, n.4, pp. 689-720.

PALMEIRA, M.; HEREDIA, B. Política ambígua. 2010. Rio de Janeiro: Relume-Dumará NUAP.

PIATTONI, S. 2001. Clientelism, Interests and Democratic Representation. Cambridge University Press.

ROCHA, M. M,; BARBOSA, C. F. 2008. "Regras, incentivos e comportamento: as comissões parlamentares nos países do Cone Sul". Curitiba: Revista de Sociologia Política, v. $16, \mathrm{n}^{\circ}$ suplementar, p. 93-104, agosto.

SAMUELS, D. 1997. "Determinantes do Voto Partidário em Sistemas Eleitorais Centrados no Candidato: Evidências sobre o Brasil”. Dados, Rio de Janeiro, v. 40, n. 3.

SOARES, G. A. D.; TERRON, S. 2008. "Dois Lulas: a geografia eleitoral da reeleição (explorando conceitos, métodos e técnicas de análise geoespacial)". Opinião Pública, Campinas, v. 14, n. 2, Nov.

TSE, Tribunal Superior Eleitoral. Disponível em: www.tse.jus.br. Acesso em 10/07/2013. 